\title{
When to stop septic shock resuscitation: clues from a dynamic perfusion monitoring
}

\author{
Glenn Hernandez ${ }^{*}$, Cecilia Luengo ${ }^{2}$, Alejandro Bruhn, Eduardo Kattan', Gilberto Friedman², \\ Gustavo A Ospina-Tascon ${ }^{4}$, Andrea Fuentealba ${ }^{1}$, Ricardo Castro ${ }^{1}$, Tomas Regueira ${ }^{1}$, Carlos Romero ${ }^{2}$, Can Ince ${ }^{5}$ \\ and Jan Bakker ${ }^{5}$
}

\begin{abstract}
Background: The decision of when to stop septic shock resuscitation is a critical but yet a relatively unexplored aspect of care. This is especially relevant since the risks of over-resuscitation with fluid overload or inotropes have been highlighted in recent years. A recent guideline has proposed normalization of central venous oxygen saturation and/or lactate as therapeutic end-points, assuming that these variables are equivalent or interchangeable. However, since the physiological determinants of both are totally different, it is legitimate to challenge the rationale of this proposal. We designed this study to gain more insights into the most appropriate resuscitation goal from a dynamic point of view. Our objective was to compare the normalization rates of these and other potential perfusion-related targets in a cohort of septic shock survivors.

Methods: We designed a prospective, observational clinical study. One hundred and four septic shock patients with hyperlactatemia were included and followed until hospital discharge. The 84 hospital-survivors were kept for final analysis. A multimodal perfusion assessment was performed at baseline, 2, 6, and $24 \mathrm{~h}$ of ICU treatment.

Results: Some variables such as central venous oxygen saturation, central venous-arterial $\mathrm{pCO}_{2}$ gradient, and capillary refill time were already normal in more than $70 \%$ of survivors at $6 \mathrm{~h}$. Lactate presented a much slower normalization rate decreasing significantly at $6 \mathrm{~h}$ compared to that of baseline (4.0 [3.0 to 4.9] vs. 2.7 [2.2 to 3.9] $\mathrm{mmol} / \mathrm{L} ; p<0.01$ ) but with only $52 \%$ of patients achieving normality at $24 \mathrm{~h}$. Sublingual microcirculatory variables exhibited the slowest recovery rate with persistent derangements still present in almost $80 \%$ of patients at $24 \mathrm{~h}$.

Conclusions: Perfusion-related variables exhibit very different normalization rates in septic shock survivors, most of them exhibiting a biphasic response with an initial rapid improvement, followed by a much slower trend thereafter. This fact should be taken into account to determine the most appropriate criteria to stop resuscitation opportunely and avoid the risk of over-resuscitation.
\end{abstract}

Keywords: Septic shock; Perfusion; Resuscitation; Lactate; Microcirculation

\section{Background}

Several clinical studies have demonstrated that persistent impairment of perfusion-related physiological variables is associated with increased mortality in septic shock patients [1-3]. Therefore, current guidelines recommend normalization of relevant physiologic variables such as lactate and/or central venous oxygen saturation $\left(\mathrm{ScvO}_{2}\right)$ as resuscitation goals, basically through oxygen transport

\footnotetext{
* Correspondence: glennguru@gmail.com

${ }^{1}$ Departamento de Medicina Intensiva, Facultad de Medicina, Pontificia Universidad Católica de Chile, Marcoleta 367, Santiago 8320000, Chile Full list of author information is available at the end of the article
}

$\left(\mathrm{DO}_{2}\right)$ optimization $[4,5]$. In addition, peripheral perfusion, central venous-arterial $\mathrm{pCO}_{2}$ gradient $\left(\mathrm{P}(\mathrm{cv}-\mathrm{a}) \mathrm{CO}_{2}\right)$, and microcirculatory abnormalities have also been linked to morbidity or mortality and suggested as potential complementary targets [6-8].

However, the issue of when to stop resuscitation has become more relevant in recent years as the risks of overresuscitation have also been increasingly highlighted. In fact, pursuing complete normalization of all potential perfusion-related goals with repeated attempts to increase $\mathrm{DO}_{2}$ could eventually result in severe adverse effects such as fluid overload, pulmonary edema, intra-abdominal 
hypertension, cardiac arrhythmias, and myocardial ischemia, thus possibly increasing morbidity and mortality [9-11].

From a physiological point of view, the problem is far more complex. For instance, it is not known if all perfusion-related variables are equally sensitive to $\mathrm{DO}_{2}$ optimization [12], a factor that could critically influence their specific normalization rates. Besides, parameters traditionally considered as reflecting tissue perfusion like lactate are also mechanistically determined by non-flow dependent or mixed mechanisms [13]. This may result in a wide variability on individual recovery time courses after optimization of $\mathrm{DO}_{2}$ depending on the predominant pathogenic mechanism. The practical aspect is that if a more likely flow-dependent parameter is selected as a goal (such as $\mathrm{P}(\mathrm{cv}-\mathrm{a}) \mathrm{CO}_{2}$ or $\mathrm{ScvO}_{2}$ ), it may normalize earlier than a less flow-dependent one such as lactate. In other words, from a theoretical point of view, the resuscitation length could vary dramatically depending on these considerations leading eventually to the risk of over-resuscitation if the selected goal exhibits an intrinsic slow normalization rate.

To address this subject, we designed a prospective study to evaluate the specific normalization rates of several perfusion-related variables in a cohort of consecutive septic shock patients subjected to protocolized resuscitation and multimodal perfusion assessment. We a priori decided to include only ultimately hospital-surviving patients for analysis to provide a relevance perspective to persistent abnormalities after initial resuscitation.

\section{Methods}

\section{Setting}

We conducted a prospective observational study from July 2011 to November 2012 in a mixed 16-bed ICU at our university hospital. The institutional review board of our university approved this study and waived the need of an informed consent because of the observational nature of the study (Comité de Etica en Investigación, Facultad de Medicina, Pontificia Universidad Católica de Chile; approval number 11-113).

\section{Patient selection}

We included all consecutive adult patients admitted to the ICU with septic shock diagnosis according to the 2001 consensus definition [14], with a basal arterial lactate $>2 \mathrm{mmol} / \mathrm{L}$ and full commitment for resuscitation.

\section{Protocol and measurements}

Patients were studied for the first $24 \mathrm{~h}$ following initiation of ICU-based resuscitation and were followed until death or hospital discharge. Clinical and demographic data and severity scores $[15,16]$ were collected for each patient at baseline (at inclusion $=0 \mathrm{~h}$ ).
The following measurements as part of a multimodal perfusion assessment were obtained at baseline and at 2 , 6 , and $24 \mathrm{~h}$ after starting ICU resuscitation:

1. Macro-hemodynamic variables: mean arterial pressure (MAP), heart rate, norepinephrine (NE) or vasoactive drug doses, central venous pressure (CVP), pulse pressure variation (\%), and pulmonary artery catheter-derived values (when in place). Fluid administration was also registered at each predefined time-point.

2. Metabolic-related perfusion variables: $\mathrm{ScvO}_{2}$, arterial lactate and $\mathrm{P}(\mathrm{cv}-\mathrm{a}) \mathrm{CO}_{2}$.

3. Peripheral perfusion was assessed with the capillary refill time (CRT) (normal values $\leq 4.0 \mathrm{~s}$ ) [17].

In a subgroup of patients who arrived within the first $2 \mathrm{~h}$ of onset of septic shock and were already in mechanical ventilation, we performed also the following microcirculatory and micro-oxygenation assessments:

1. Thenar muscle oxygen saturation $\left(\mathrm{StO}_{2}\right)$ was measured by a tissue spectrometer (InSpectra Model 650, Hutchinson Technology, Minneapolis, MN, USA) [18]. A value $\geq 75 \%$ was considered as normal for this protocol. A vascular occlusion test (VOT) was performed as described elsewhere [19]. During the reperfusion phase of the VOT, the recovery slope of the $\mathrm{StO}_{2}$ signal was registered and calculated with a software (InSpectra V3-03, Hutchinson Technology, MN, USA) and expressed in percentage per second (values $>3.5 \% / \mathrm{s}$ were considered as normal for this study based on our own data in healthy volunteers (data not shown)).

2. Microcirculatory-derived variables: sublingual microcirculation was assessed with sidestream dark field video microscopy imaging (Microscan ${ }^{\circ}$ for NTSC, MicroVision Medical, Amsterdam, the Netherlands). Image acquisition and analysis were performed following recent recommendations of a consensus conference [20]. A trained independent investigator performed image analysis in all cases, and these data were not disclosed to the attending physicians or considered for management. Parameters considered for this study were proportion of perfused vessels (PPV; values $\geq 90 \%$ were considered as normal); perfused vessel density (PVD; values $\geq 14 \mathrm{n} / \mathrm{mm}$ were considered as normal); and microcirculatory flow index (MFI; values $\geq 2.5$ were considered as normal).

All patients were managed according to a local algorithm [21] aimed at macrohemodynamic stabilization and improvement of hypoperfusion abnormalities (both 
$\mathrm{ScvO}_{2}$ and lactate) during the first $24 \mathrm{~h}$ following implementation of adequate maneuvers for source control. The main strategy to improve oxygen transport/oxygen consumption unbalance was preload optimization. For this purpose, the algorithm included early fluid loading, followed by NE as needed to maintain a MAP $>65 \mathrm{mmHg}$. Further fluid resuscitation was guided by dynamic predictors (pulse pressure variation) in patients under mechanical ventilation, except in patients with atrial fibrillation [22]. To assess pulse pressure variation in patients with acute respiratory distress syndrome, we transiently increased tidal volume to $8 \mathrm{~mL} / \mathrm{kg}$. A pulmonary artery catheter was placed in patients with high NE requirements $(>0.3 \mathrm{mcg} / \mathrm{kg} / \mathrm{min})$ or past medical history of cardiac disease. In patients with atrial fibrillation and with a pulmonary artery catheter in place, volume administration was guided by a Starling curve approach in which progressive fluid boluses were administered until reaching a plateau in cardiac index. In patients with spontaneous breathing, fluid resuscitation was guided by central venous pressure criteria as suggested by current guidelines [4]. Dobutamine was restricted to patients with cardiac index $<2.2 \mathrm{~L} / \mathrm{min} / \mathrm{m}^{2}$ in whom attending physicians had ruledout hypovolemia as the cause of persistent hypoperfusion. Arterial hemoglobin oxygen saturation was maintained at $>90 \%$, and hemoglobin concentrations at $8 \mathrm{~g} / \mathrm{dl}$ or higher to optimize arterial oxygen content. Mechanical ventilation settings were adjusted according to current recommendations [4]. Intra-abdominal pressure was monitored and treated according to recent recommendations [23].

\section{Statistical analysis}

Categorical data were analyzed with chi-square or Fisher's exact test when appropriate. Repeated measures were analyzed with Friedman test with Bonferroni posthoc correction. All data are presented as medians and 25 to 75 interquartile ranges. We performed trend estimations of different perfusion and microcirculatory variables computing the average ranks for each variable using Pearson's correlation coefficient as described by Cuzick [24]. We also performed a normalization procedure for lactate, $\mathrm{P}(\mathrm{cv}-\mathrm{a}) \mathrm{CO}_{2}$, and $\mathrm{CRT}$ values to rescaling them in order to allow comparison of these parameters' relative changes in specific time periods. For each variable, the highest normal value was taken, and each individual value was divided by it. Hence, medians and interquartile ranges were plotted. Fractional polynomials analyses were done to model realistic fitting curves for each parameter trend. All reported $p$ values are twosided, with a significant alpha level at 5\%. SPSS 17 (SPSS Inc., Chicago, IL, USA) and Stata 12 (StataCorp LP, College Station, TX, USA) statistical packages were used for analyses.

\section{Results}

One hundred and four patients were admitted with a diagnosis of septic shock during the 18-month period, with a hospital mortality of $19 \%(N=20)$.

Within this group, 84 were discharged alive from the hospital and constitute our definitive study group. Thus, data regarding non-survivors were not considered for final analysis and are only provided in Additional file 1: Table S1. Basal demographic, clinical, and physiological data and severity scores of the whole population and the 84 survivors are provided in Table 1 . The main septic sources were abdominal $(n=45)$, pulmonary $(n=23)$, urinary tract $(n=8)$, and others, including soft tissue and catheter sources $(n=8)$. Sixteen patients were admitted directly from the operating room.

Patients received 1,750 [640 to 2,400] mL of crystalloids in the pre-ICU setting after meeting septic shock criteria. The rate of fluid administration tended to decrease over time during ICU resuscitation. A total of $1,150$ [600 to 1,600$] \mathrm{mL}$ of crystalloids were administered during the first $2 \mathrm{~h}, 980$ [510 to 1,410$] \mathrm{mL}$ from 3 to $6 \mathrm{~h}$, and 1,020 [290 to 2,400] $\mathrm{mL}$ from 7 to $24 \mathrm{~h}$ of ICU-based resuscitation. A pulmonary artery catheter was placed in 38 patients. Basal cardiac index and pulmonary arterial occlusion pressure were 3.1 [2.5 to 3.9] $\mathrm{L} / \mathrm{min} / \mathrm{m}^{2}$ and 17 [12 to 23 ] $\mathrm{mmHg}$, respectively. Dobutamine was used in ten patients. Basal and 24-h intraabdominal pressures were 13 [9 to 17 ] and 13 [8 to 15 ] $\mathrm{mmHg}$, respectively.

By definition, all patients started ICU-based resuscitation with an abnormal lactate as compared to only 8,31 , 32 , and 39 patients with abnormal $\mathrm{ScvO}_{2}, \mathrm{StO}_{2}, \mathrm{P}(\mathrm{cv}-\mathrm{a})$ $\mathrm{CO}_{2}$, and CRT values, respectively. Medians values for individual macrohemodynamic and perfusion variables at different time-points in patients with abnormal values at baseline are shown in Table 2. Lactate decreased significantly from 0 to $6 \mathrm{~h}(4.0$ [3.0 to 4.9$]$ vs. 2.7 [2.2 to 3.9] $\mathrm{mmol} / \mathrm{L} ; p<0.01)$.

When analyzing the time-trend changes of lactate, $\mathrm{P}$ (cv-a) $\mathrm{CO}_{2}$, and CRT values, a biphasic curve could be drawn (Figure 1) where a rapid decrease in every variable during the first $6 \mathrm{~h}$ was followed by a slower decay thereafter.

Medians values for microcirculatory variables and the percentage of normalization for lactate, $\mathrm{P}(\mathrm{cv}-\mathrm{a}) \mathrm{CO}_{2}, \mathrm{CRT}$, and microcirculatory variables at different time-points for the subgroup of patients arriving within the first $2 \mathrm{~h}$ of septic shock are shown in Table 3 and Figure 2, respectively. In these patients, lactate levels dropped to normal in $52 \%$ of the patients at $24 \mathrm{~h}$. During follow-up of the 40 remaining patients with persistent hyperlactatemia at $24 \mathrm{~h}, 24$ normalized lactate at $48 \mathrm{~h}$, ten at $72 \mathrm{~h}$, and six up to the seventh day. In contrast, microcirculatory variables remained abnormal in the majority of the patients, even at 
Table 1 General characteristics of the study population

\begin{tabular}{|c|c|c|c|c|}
\hline Parameters & Total patients & Survivors without MC & Survivors with MC & $p$ value between survivors \\
\hline Number & 104 & 53 & 31 & \\
\hline Age (years) & $66[56$ to 75$]$ & $63[52$ to 71$]$ & $67[56$ to 76$]$ & 0.4 \\
\hline Male/female (\%) & $45 / 55$ & $47 / 53$ & $39 / 61$ & 0.3 \\
\hline APACHE $\|$ & 23 [19 to 26$]$ & 23 [18 to 27] & 24 [19 to 27$]$ & 0.5 \\
\hline Basal SOFA & $10[8$ to 13$]$ & $10[8$ to 13$]$ & $10[8$ to 13$]$ & 0.9 \\
\hline 24 h SOFA & $10[7$ to 12$]$ & $10[7$ to 12$]$ & $11[10$ to 13$]$ & 0.6 \\
\hline Length of hospital stay (days) & 23 [15 to 35$]$ & 24 [16 to 36$]$ & 24 [15 to 43$]$ & 0.8 \\
\hline Length of ICU stay (days) & $11[7$ to 17$]$ & $11[7$ to 25$]$ & $10[7$ to 16$]$ & 0.5 \\
\hline MV duration (days) & $8[5$ to 15$]$ & $9[5$ to 15$]$ & $8[5$ to 14$]$ & 0.4 \\
\hline Basal NE requirements (mcg/kg/min) & $0.11[0.03$ to 0.30$]$ & $0.10[0.04$ to 0.28$]$ & $0.16[0.03$ to 0.34$]$ & 0.4 \\
\hline Basal lactate $(\mathrm{mmol} / \mathrm{L})$ & $4.0[3.0$ to 4.9$]$ & $4.2[3.0$ to 5.3$]$ & $4.0[2.8$ to 4.9$]$ & 0.9 \\
\hline
\end{tabular}

Values are expressed as median [interquartile range] or percentage. MC, microcirculatory assessment; APACHE II, acute physiology and chronic health evaluation II; SOFA, sequential organ failure assessment; ICU, intensive care unit; MV, mechanical ventilation; NE, norepinephrine.

$24 \mathrm{~h}$ (Figure 2). No difference in SOFA scores (9 [7 to 11] vs. 11 [8 to 15$] ; p=0.2)$ or NE requirements $(0.01$ [0 to 0.04 ] vs. 0.17 [ 0 to 0.24 ]; $p=0.16$ ) was observed between patients that had normalized lactate or not at $24 \mathrm{~h}$.

\section{Discussion}

Perfusion-related variables exhibit markedly different normalization rates in septic shock survivors, most of them exhibiting a biphasic response with an initial rapid improvement, followed by a much slower trend thereafter. This fact should be taken into account to determine the most appropriate criteria to stop resuscitation opportunely and avoid the risk of over-resuscitation.

Central venous oxygen saturation, $\mathrm{P}(\mathrm{cv}-\mathrm{a}) \mathrm{CO}_{2}$, and CRT values were already normal in the majority of patients at ICU admission after some previous volume loading, and it appears that these variables are particularly responsive to $\mathrm{DO}_{2}$ increasing maneuvers. In a previous study, $\mathrm{ScvO}_{2}$, increased from $49 \%$ to $77 \%$ in septic shock patients subjected to early aggressive $\mathrm{DO}_{2}$ optimization [3]. The sensitivity of $\mathrm{ScvO}_{2}$ to pre-ICU fluid loading probably explains the almost negligible incidence of low $\mathrm{ScvO}_{2}$ values in the ICU setting $[25,26]$. CRT may also improve rapidly after fluid resuscitation, and we found that normality of CRT values increased from $46 \%$ to $70 \%$ after $2 \mathrm{~h}$ of resuscitation. Changes in $\mathrm{ScvO}_{2}, \mathrm{P}(\mathrm{cv}-\mathrm{a}) \mathrm{CO}_{2}$, and $\mathrm{CRT}$ appeared to become slower after $6 \mathrm{~h}$, eventually representing the influence of non-flow dependent mechanisms on the remaining abnormalities $[6,27,28]$.

The case of hyperlactatemia is paradigmatic. Although tissue hypoperfusion has been traditionally considered

Table 2 Evolution of different perfusion and hemodynamic parameters in a cohort of 84 hospital survivors

\begin{tabular}{|c|c|c|c|c|c|c|}
\hline Perfusion parameters & $\begin{array}{l}\text { Number of patients with altered } \\
\text { baseline values }\end{array}$ & Baseline & $2 \mathrm{~h}$ & $6 \mathrm{~h}$ & $24 \mathrm{~h}$ & $p$ value $^{a}$ \\
\hline Lactate (mmol/L) & 84 & $4.0[3.0$ to 4.9$]$ & $3.4[2.4$ to 4.2$]$ & $2.8[2.0$ to 3.8$]$ & $1.8[1.4$ to 2.5$]$ & $<0.001$ \\
\hline $\mathrm{P}(\mathrm{cv}-\mathrm{a}) \mathrm{CO}_{2}(\mathrm{mmHg})$ & 34 & $8[7$ to 9$]$ & $6[5$ to 8$]$ & $5[3$ to 7$]$ & $4[3$ to 6$]$ & $<0.001$ \\
\hline CRT (s) & 43 & $6[5$ to 8$]$ & $4[3$ to 5$]$ & $3[2$ to 6$]$ & $2[2$ to 4$]$ & 0.001 \\
\hline $\mathrm{ScvO}_{2}(\%)$ & 8 & $62[58$ to 67$]$ & $65[60$ to 69$]$ & $71[70$ to 74$]$ & $74[70$ to 79$]$ & 0.001 \\
\hline $\begin{array}{l}\text { Hemodynamic } \\
\text { parameters }\end{array}$ & Number of patients assessed & Baseline & $2 \mathrm{~h}$ & $6 \mathrm{~h}$ & $24 \mathrm{~h}$ & $p$ value $^{\mathrm{a}}$ \\
\hline $\mathrm{Cl}\left(\mathrm{L} / \mathrm{min} / \mathrm{m}^{2}\right)$ & 38 & $3.1[2.5$ to 3.9$]$ & $3.5[2.9$ to 4.6$]$ & $3.2[2.6$ to 3.8$]$ & $2.8[2.4$ to 4.1$]$ & NS \\
\hline Pulse pressure variation (\%) & 63 & 6 [3 to 8] & 5 [2 to 8$]$ & $6[2$ to 8$]$ & 5 [4 to 9$]$ & NS \\
\hline CVP $(\mathrm{mmHg})$ & 84 & $13[9$ to 17$]$ & $14[10$ to 16$]$ & $14[10$ to 16$]$ & $14[11$ to 17$]$ & NS \\
\hline MAP (mm Hg) & 84 & $73[67$ to 79$]$ & $71[68$ to 74$]$ & $71[68$ to 74$]$ & $72[70$ to 77$]$ & NS \\
\hline NE dose (mcg/kg/min) & 84 & $0.11[0.04$ to 0.3$]$ & $0.18[0.06$ to 0.31$]$ & $0.17[0.07$ to 0.35$]$ & $0.05[0$ to 0.23$]$ & NS \\
\hline IAP $(\mathrm{mmHg})$ & 72 & 12 [9 to 15$]$ & 11 [9 to 13] & $12[9$ to 12$]$ & 11 [8 to 14 ] & NS \\
\hline
\end{tabular}

Values are expressed as median [interquartile range]. ${ }^{\mathrm{a}} \mathrm{Comparison}$ within group of variables was made with non-parametric trend. $\mathrm{p}(\mathrm{cv}-\mathrm{a}) \mathrm{CO}_{2}$, central venous to arterial $\mathrm{pCO}{ }_{2}$ gradient; $\mathrm{CRT}$, capillary refill time; $\mathrm{ScvO}_{2}$, central venous oxygen saturation; $\mathrm{Cl}$, cardiac index; $\mathrm{CVP}$, central venous pressure; MAP, mean arterial pressure; $\mathrm{NE}$, norepinephrine; IAP, intra-abdominal pressure. 

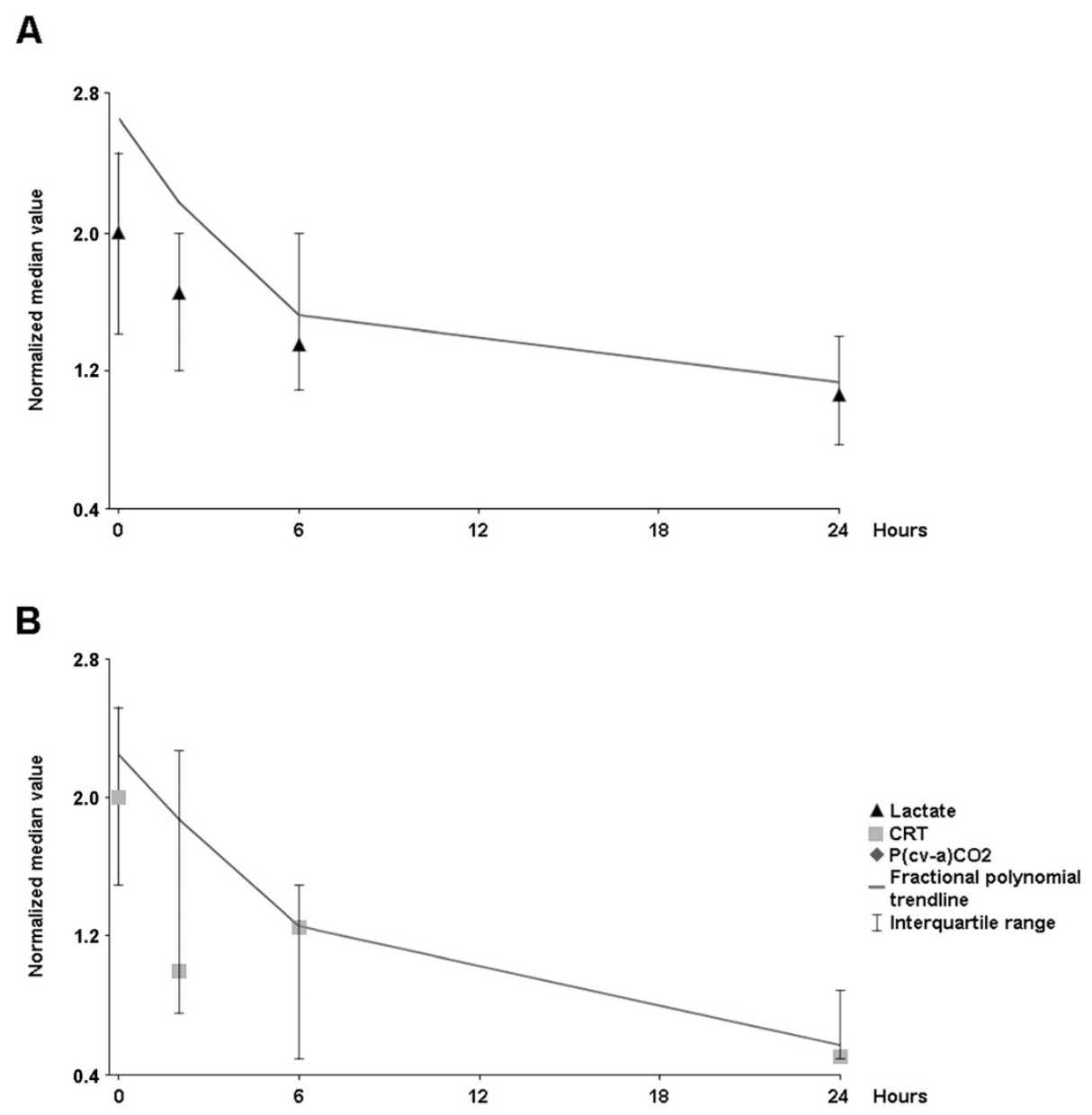

C

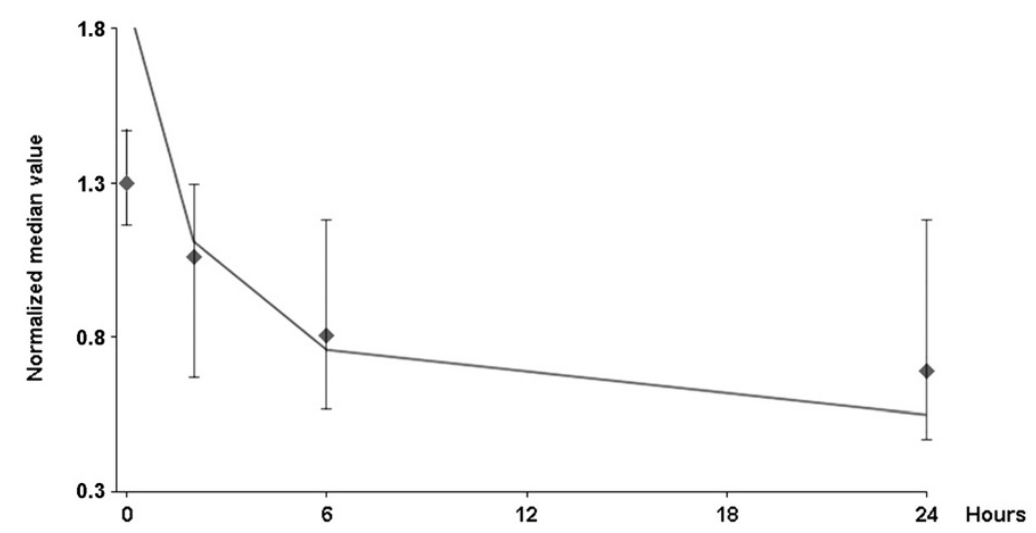

Figure 1 Time-trend changes for selected perfusion parameters after normalization showing a biphasic recovery trend (see statistical analysis): A, lactate; $\mathrm{B}$, capillary refill time (CRT); $\mathrm{C}$, central venous-arterial $p \mathrm{CO}_{2}$ gradient $\left(\mathrm{P}(\mathrm{cv}-\mathrm{a}) \mathrm{CO}_{2}\right)$.

the most common cause of hyperlactatemia, there is increasing evidence for concomitant non-hypoxic and thus, non-flow dependent mechanisms $[28,29]$ that may influence the time course of lactate recovery rate. The distinction between these two scenarios (flow-responsive vs. non-flow dependent hyperlactatemia) should strongly impact the therapeutic approach [13].

As an example, treatment of the latter with sustained efforts aimed at increasing $\mathrm{DO}_{2}$ could lead to detrimental effects of excessive fluids or inotropes. In our study, 
Table 3 Evolution of microcirculatory parameters in a cohort of $\mathbf{3 1}$ hospital survivors

\begin{tabular}{lllllll}
\hline Perfusion parameters & $\begin{array}{l}\text { Number of patients with } \\
\text { altered baseline values }\end{array}$ & Baseline & $\mathbf{2} \mathbf{h}$ & $\mathbf{6} \mathbf{h}$ & $\mathbf{2 4} \mathbf{h}$ & $\mathbf{p}$ value \\
\hline $\mathrm{PPV}(\%)$ & 30 & $69[62$ to 75$]$ & $70[68$ to 78$]$ & $71[67$ to 79$]$ & $77[68$ to 83$]$ & 0.04 \\
$\mathrm{MFI}($ score) & 28 & $1.9[1.5$ to 2.2$]$ & $2.0[1.6$ to 2.2] & $2.1[1.8$ to 2.3] & $2.2[2.0$ to 2.5] & 0.003 \\
$\mathrm{StO}_{2}(\%)$ & 8 & $72[65$ to 74$]$ & $73.5[71$ to 76] & $75.5[69$ to 84$]$ & $77[68$ to 85$]$ & $\mathrm{NS}$ \\
$\mathrm{StO}_{2}$ recovery slope (\%/s) & 23 & $1.72[0.6$ to 2.0] & $1.76[0.7$ to 2.7] & $1.70[1.2$ to 2.8] & $2.0[1.6$ to 3.1] & 0.055 \\
\hline
\end{tabular}

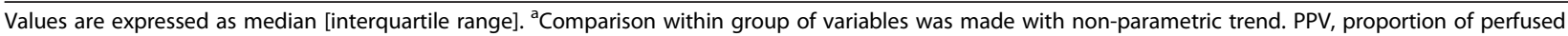
vessels; $\mathrm{MFI}$, microcirculatory flow index; $\mathrm{PVD}$, perfused vessel density; $\mathrm{StO}_{2}$, tissue oxygen saturation.

lactate exhibited a significant decrease of almost $50 \%$ of basal median values during the first $6 \mathrm{~h}$ of resuscitation associated with a rapid normalization of other metabolic and peripheral perfusion parameters (Figure 1). However, further decrease in lactate was very slow since lactate of $48 \%$ of patients was normalized beyond the first ICU day. This behavior may raise a doubt whether these patients would have benefited from more volume loading. Nevertheless, as negative dynamic predictors or a plateau Starling curve discarded further fluid responsiveness, we had no objective evidence that persistent hyperlactatemia could be addressed to ongoing flow dependent mechanisms. Thus, it appears that lactate decrease can be characterized by a biphasic evolution: an early rapid response followed by a later slower recovery trend potentially explained by non-flow dependent mechanisms. Indeed, a recently published therapeutic algorithm focused lactate-driven resuscitation exclusively in the first $8 \mathrm{~h}$ of
ICU management with a significant favorable impact on outcome [30].

In the present study, sublingual microcirculatory variables exhibited the slowest recovery rate. Moreover, since concomitant clinical and metabolic perfusion variables were already normal in the great majority of our patients, it appears as highly unlikely that persistent microcirculatory abnormalities may respond to additional fluids or $\mathrm{DO}_{2}$ optimization maneuvers after $24 \mathrm{~h}$ of resuscitation. In fact, fluid loading after $48 \mathrm{~h}$ of sepsis failed to improve microcirculatory derangements in a recent report [31]. The time-course of microcirculatory recovery during septic shock resuscitation may also follow a biphasic pattern with an early apparently flow-responsive phase [32,33]. However, further improvements appear to be much slower with full recovery taking several days $[8,34]$. The recovery slope of $\mathrm{StO}_{2}$ after a VOT maneuver was moderately abnormal in all patients, and like microcirculatory derangements, it

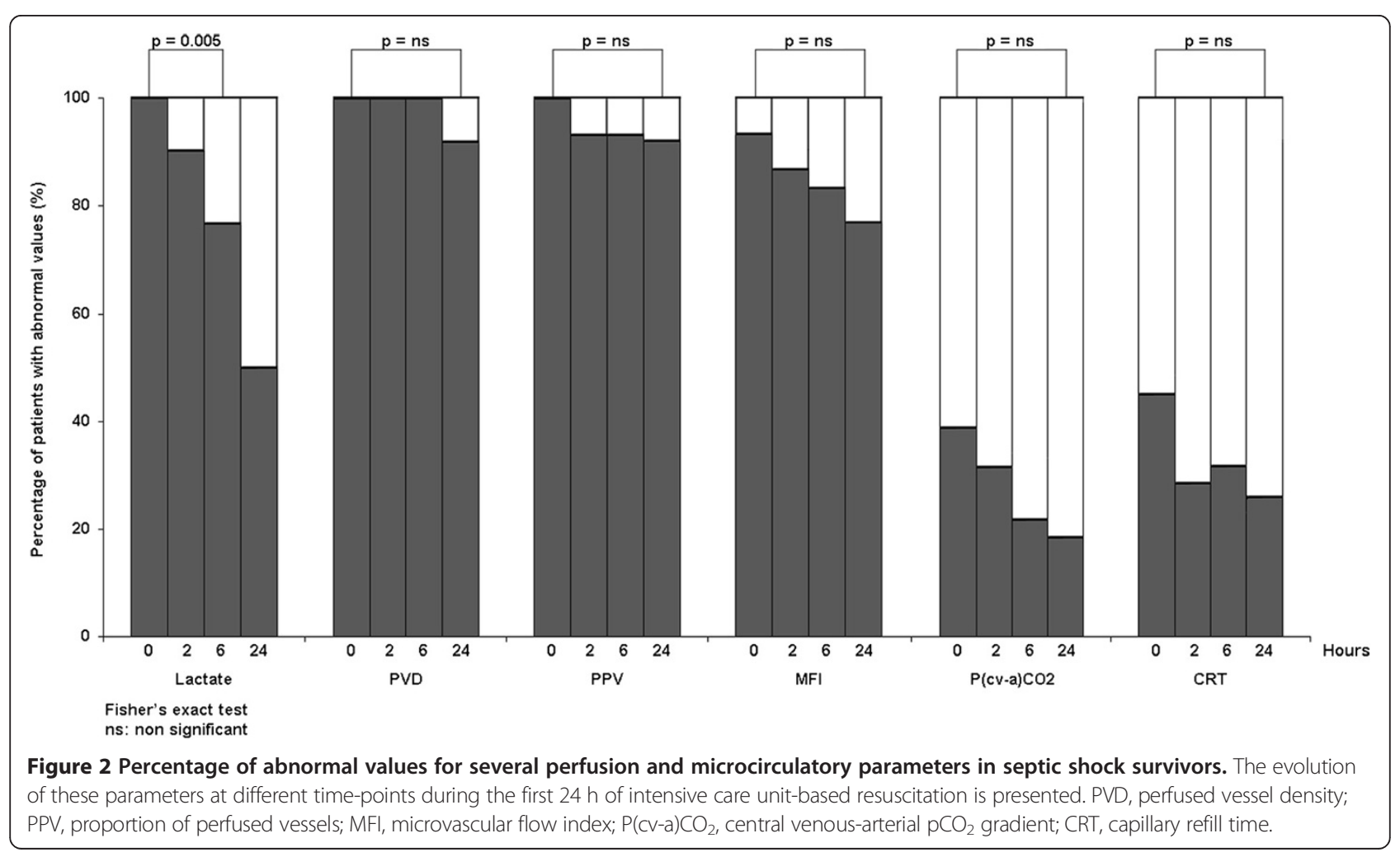


showed a very slow recovery trend without significant improvement at $24 \mathrm{~h}$. Taken together, our current and previous data suggest that persistent microcirculatory abnormalities after $24 \mathrm{~h}$ of resuscitation may represent different pathogenic mechanisms not responsive to $\mathrm{DO}_{2}$ increasing maneuvers.

How can we conceptualize our results? The critical decision to stop resuscitation is complex and should probably be taken after a multimodal perfusion assessment has been performed. The normalization of some variables such as $\mathrm{ScvO}_{2}$, lactate, or CRT is clearly a good signal, but eventually their normalization trend is more important than absolute values at certain periods. In practical terms, resuscitation would have been stopped at admission in $90 \%$ of these patients by using the single criterion of a normal $\mathrm{ScvO}_{2}$ but only in $52 \%$ of patients at $24 \mathrm{~h}$ by using a normal lactate criterion. Our study was not designed to establish which criterion is better, but it does suggest that the length of septic shock resuscitation may vary dramatically depending on the selected perfusion goal and that the different potential targets are not equivalent or interchangeable as suggested by a recent guideline [4]. Since ours is only a hypothesisgenerating study, these findings should be explored and confirmed in future studies, since as mentioned before an excess in resuscitation efforts may lead to severe side effects.

Finally, due to the complexity of the pathogenic mechanisms influencing each of the perfusion variables, and of their dynamic characteristics, it is clear that treatment of septic shock may also be guided by the presence of comorbidities, adequacy of source control, and the degree of systemic inflammation, among others.

We acknowledge several potential limitations of our study. This cohort exhibited a low mortality rate. Therefore, our findings may not be universally extrapolated. However, several recent studies report a mortality of around $20 \%$ in septic shock patients undergoing early resuscitation, especially when the main source is abdominal [35-37]. Second, the study period may be considered not long enough and the selected time points are arbitrary. Third, this is a single center study that limits its application to other settings and centers. Fourth, due to the design of this study, we cannot determine if changes in perfusion variables over time can be ascribed to the natural evolution of disease or to the effects of some specific treatment. Fifth, although our findings suggest that the length of the resuscitation process could vary dramatically according to the selected perfusion goal, we do not know if this effectively leads to over-resuscitation in some cases since our study was not designed to establish this point. Finally, since only surviving patients compose our cohort, we know that the main endpoint of any septic shock resuscitation strategy was successfully achieved. However, we do not know if additional resuscitation could have further reduced morbidity. Nevertheless, the lack of difference in 24-h SOFA scores or NE requirements between patients who normalized lactate vs. those who did not makes this possibility unlikely. Furthermore, as dynamic predictors of fluid responsiveness were persistently negative, there is no evidence that additional resuscitation could have benefited secondary outcomes, especially considering controversial data concerning other potential therapies such as dobutamine or nitroglycerine $[38,39]$.

\section{Conclusions}

In conclusion, these results demonstrate that perfusionrelated variables exhibit markedly different normalization rates in septic shock survivors, most of them showing a biphasic response with an initial rapid improvement, followed by a much slower trend thereafter. The length of septic shock resuscitation may vary dramatically depending on the selected perfusion goal. This fact should be taken into account to determine the most appropriate criteria to stop resuscitation opportunely and avoid the risk of over-resuscitation.

\section{Additional file}

Additional file 1: Table S1. Hemodynamic and perfusion-related parameters in 20 non-survivors.

\section{Abbreviations}

APACHE: Acute physiology and chronic health evaluation; CVP: central venous pressure; CRT: capillary refill time; $\mathrm{DO}_{2}$ : oxygen transport; IAP: intra-abdominal pressure; ICU: intensive care unit; MAP: mean arterial pressure;

MFI: microcirculatory flow index; NE: norepinephrine; NIRS: near-infrared spectroscopy; $\mathrm{P}(\mathrm{v}-\mathrm{a}) \mathrm{CO}_{2}$ : mixed venous to arterial $\mathrm{pCO}_{2}$ gradient; PPV: proportion of perfused vessels; PVD: perfused vascular density; SOFA: Sequential Organ Failure Assessment; $\mathrm{ScvO}_{2}$ : central venous oxygen saturation; $\mathrm{StO}_{2}$ : tissue oxygen saturation; $\mathrm{SvO}_{2}$ : mixed venous oxygen saturation; VOT: vascular occlusion test.

\section{Competing interests}

The authors declare that they have no competing interests.

\section{Authors' contributions}

$\mathrm{GH}, \mathrm{CL}$, and $\mathrm{AB}$ conceived the study, participated in its design and coordination, and helped to draft the manuscript. JB, Cl, GF, and GO conceived the study and helped to draft the manuscript. RC helped to draft the manuscript and performed statistical analyses. EK maintained the database, performed statistical analyses, and designed tables and figures. AF registered and analyzed microcirculatory images. CR recruited and followed up patients. TR recruited and followed up patients. All authors read and approved the final manuscript.

\section{Acknowledgements}

The study was funded by an institutional grant of the Departamento de Medicina Intensiva, Facultad de Medicina, Pontificia Universidad Católica de Chile.

\section{Author details}

'Departamento de Medicina Intensiva, Facultad de Medicina, Pontificia Universidad Católica de Chile, Marcoleta 367, Santiago 8320000, Chile. ${ }^{2}$ Unidad de Pacientes Críticos, Hospital Clínico, Universidad de Chile, Santos Dumont 999, Santiago 8380456, Chile. ${ }^{3}$ Department of Critical Care Medicine, 
Hospital de Clínicas de Porto Alegre, Rua Ramiro Barcelos, 2350, 90035-903 Porto Alegre-RS, Brazil. ${ }^{4}$ Intensive Care Unit, Fundación Valle del Lili, Av. Simón Bolívar Cra 98 \# 18-49, Cali, Valle del Cauca, Colombia. ${ }^{5}$ Department of Intensive Care Adults, Erasmus MC University Medical Centre, Doctor Molewaterplein 50-60, Rotterdam, the Netherlands.

Received: 10 April 2014 Accepted: 6 August 2014

Published online: 11 October 2014

\section{References}

1. Hernandez G, Bruhn A, Castro R, Pedreros C, Rovegno M, Kattan E, Veas E, Fuentealba A, Regueira T, Ruiz C, Ince C: Persistent sepsis-induced hypotension without hyperlactatemia: is it really septic shock? $J$ Crit Care 2011, 26(435):e9-e14

2. Palizas F, Dubin A, Regueira T, Bruhn A, Knobel E, Lazzeri S, Baredes N, Hernández G: Gastric tonometry versus cardiac index as resuscitation goals in septic shock: a multicenter, randomized, controlled trial. Crit Care 2009, 13:R44.

3. Rivers E, Nguyen B, Havstad S, Ressler J, Muzzin A, Knoblich B, Peterson E, Tomlanovich M: Early goal-directed therapy in the treatment of severe sepsis and septic shock. N Engl J Med 2001, 345:1368-1377.

4. Dellinger RP, Levy MM, Rhodes A, Annane D, Gerlach H, Opal SM, Sevransky JE, Sprung CL, Douglas IS, Jaeschke R, Osborn TM, Nunnally ME, Townsend SR, Reinhart K, Kleinpell RM, Angus DC, Deutschman CS, Machado FR, Rubenfeld GD, Webb S, Beale RJ, Vincent JL, Moreno R, Surviving Sepsis Campaign Guidelines Committee including The Pediatric Subgroup: Surviving sepsis campaign: international guidelines for management of severe sepsis and septic shock. Intensive Care Med 2013, 39:165-228.

5. Green RS, Djogovic D, Gray S, Howes D, Brindley PG, Stenstrom R, Patterson E, Easton D, Davidow JS, CAEP Critical Care Interest Group: Canadian association of emergency physicians sepsis guidelines: the optimal management of severe sepsis in Canadian emergency departments. CJEM 2008, 10:443-459.

6. Lima A, Jansen TC, van Bommel J, Ince C, Bakker J: The prognostic value of the subjective assessment of peripheral perfusion in critically ill patients. Crit Care Med 2009, 37:934-938.

7. Vallée F, Vallet B, Mathe O, Parraquette J, Mari A, Silva S, Samii K, Fourcade $\mathrm{O}$, Genestal M: Central venous-to-arterial carbon dioxide difference: an additional target for goal-directed therapy in septic shock? Intensive Care Med 2008, 34:2218-2225.

8. Sakr Y, Dubois MJ, De Backer D, Creteur J, Vincent JL: Persistent microcirculatory alterations are associated with organ failure and death in patients with septic shock. Crit Care Med 2004, 32:1825-1831.

9. Hayes MA, Timmins AC, Yau EH, Palazzo M, Hinds CJ, Watson D: Elevation of systemic oxygen delivery in the treatment of critically ill patients. N Engl J Med 1994, 330:1717-1722.

10. Enrico C, Kanoore Edul VS, Vazquez AR, Pein MC, de la Hoz RAP, Ince C, Dubin A: Systemic and microcirculatory effects of dobutamine in patients with septic shock. J Crit Care 2012, 27:630-638.

11. Regueira T, Bruhn A, Hasbun P, Aguirre M, Romero C, Llanos O, Castro R, Bugedo G, Hernandez G: Intra-abdominal hypertension: incidence and association with organ dysfunction during early septic shock. J Crit Care 2008, 23:461-467.

12. Jones $A E$, Shapiro NI, Trzeciak S, Arnold RC, Claremont HA, Kline JA, Emergency Medicine Shock Research Network (EMShockNet) Investigators: Lactate clearance vs central venous oxygen saturation as goals of early sepsis therapy: a randomized clinical trial. JAMA 2010, 303:739-746.

13. Hernandez G, Bruhn A, Castro R, Regueira T: The holistic view on perfusion monitoring in septic shock. Curr Opin Crit Care 2012, 18:280-286.

14. Levy MM, Fink MP, Marshall JC, Abraham E, Angus D, Cook D, Cohen J, Opal SM, Vincent JL, Ramsay G, SCCM/ESICM/ACCP/ATS/SIS: 2001 international sepsis definitions conference. Crit Care Med 2003, 31:1250-1256.

15. Knaus WA, Draper EA, Wagner DP, Zimmerman JE: APACHE II: a severity of disease classification system. Crit Care Med 1985, 13:818-829.

16. Vincent JL, Moreno R, Takala J, Willatts S, De Mendonça A, Bruining H, Reinhart CK, Suter PM, Thiis LG: The SOFA (sepsis-related organ failure assessment) score to describe organ dysfunction/failure: on behalf of the working group on sepsis-related problems of the European society of intensive care medicine. Intensive Care Med 1996, 22:707-710.

17. Hernandez G, Pedreros C, Veas E, Bruhn A, Romero C, Rovegno M, Neira R, Bravo $\mathrm{S}$, Castro R, Kattan E, Ince C: Evolution of peripheral vs metabolic perfusion parameters during septic shock resuscitation: a clinical-physiologic study. J Crit Care 2012, 27:283-288.

18. Mesquida J, Masip J, Gili G, Artigas A, Baigorri F: Thenar oxygen saturation measured by near infrared spectroscopy as a noninvasive predictor of low central venous oxygen saturation in septic patients. Intensive Care Med 2009, 35:1106-1109.

19. Shapiro NI, Arnold R, Sherwin R, O'Connor J, Najarro G, Singh S, Lundy D, Nelson T, Trzeciak SW, Jones AE, Emergency Medicine Shock Research Network (EMShockNet): The association of near-infrared spectroscopy-derived tissue oxygenation measurements with sepsis syndromes, organ dysfunction and mortality in emergency department patients with sepsis. Crit Care 2011, 15:R223.

20. De Backer D, Hollenberg S, Boerma C, Goedhart P, Büchele G, Ospina-Tascon $\mathrm{G}$, Dobbe I, Ince C: How to evaluate the microcirculation: report of a round table conference. Crit Care 2007, 11:R101.

21. Cornejo R, Downey P, Castro R, Romero C, Regueira T, Vega J, Castillo L, Andresen M, Dougnac A, Bugedo G, Hernandez G: High-volume hemofiltration as salvage therapy in severe hyperdynamic septic shock. Intensive Care Med 2006, 32:713-722.

22. Marik PE, Monnet $X$, Teboul JL: Hemodynamic parameters to guide fluid therapy. Ann Intensive Care 2011, 1:1. doi:10.1186/2110-5820-1-1.

23. Balogh ZJ, Malbrain M: Resuscitation in intra-abdominal hypertension and abdominal compartment syndrome. Am Surg 2011, 77(Suppl 1):S31-S33.

24. Cuzick J: A wilcoxon-type test for trend. Stat Med 1985, 4:87-90.

25. Bracht $H$, Hänggi $M$, Jeker B, Wegmüller N, Porta F, Tüller D, Takala J, Jakob SM: Incidence of low central venous oxygen saturation during unplanned admissions in a multidisciplinary intensive care unit: an observational study. Crit Care 2007, 11:R2

26. Van Beest PA, Hofstra HH, Schultz MJ, Boerma EC, Spronk PE, Kuiper MA: The incidence of low venous oxygen saturation on admission to the intensive care unit: a multi-centre observational study in The Netherlands. Crit Care 2008, 12:R33.

27. Van Genderen ME, Lima A, Akkerhuis M, Bakker J, Van Bommel J: Persistent peripheral and microcirculatory perfusion alterations after out-of-hospital cardiac arrest are associated with poor survival. Crit Care Med 2012, 40:2287-2294.

28. Levy B: Lactate and shock state: the metabolic view. Curr Opin Crit Care 2006, 12:315-321.

29. Hernandez G, Regueira T, Bruhn A, Castro R, Rovegno M, Fuentealba A, Veas E, Berrutti D, Florez J, Kattan E, Martin C, Ince C: Relationship of systemic, hepatosplanchnic, and microcirculatory perfusion parameters with 6-hour lactate clearance in hyperdynamic septic shock patients: an acute, clinical-physiological, pilot study. Ann Intensive Care 2012, 2:44.

30. Jansen TC, Van Bommel J, Schoonderbeek FJ, Sleeswijk Visser SJ, Van der Klooster JM, Lima AP, Willemsen SP, Bakker J, LACTATE study group: Early lactate-guided therapy in intensive care unit patients: a multicenter, open-label, randomized controlled trial. Am J Respir Crit Care Med 2010, 182:752-761.

31. Ospina-Tascon G, Neves AP, Occhipinti G, Donadello K, Büchele G, Simion D, Chierego ML, Silva TO, Fonseca A, Vincent JL, De Backer D: Effects of fluids on microvascular perfusion in patients with severe sepsis. Intensive Care Med 2010, 36:949-955.

32. Trzeciak S, McCoy JV, Phillip Dellinger R, Arnold RC, Rizzuto M, Abate NL, Shapiro NI, Parrillo JE, Hollenberg SM, Microcirculatory Alterations in Resuscitation and Shock (MARS) investigators: Early increases in microcirculatory perfusion during protocol-directed resuscitation are associated with reduced multi-organ failure at $24 \mathrm{~h}$ in patients with sepsis. Intensive Care Med 2008, 34:2210-2217.

33. Pottecher J, Deruddre S, Teboul JL, Georger JF, Laplace C, Benhamou D, Vicaut $E$, Duranteau J: Both passive leg raising and intravascular volume expansion improve sublingual microcirculatory perfusion in severe sepsis and septic shock patients. Intensive Care Med 2010, 36:1867-1874.

34. De Backer D, Donadello K, Sakr Y, Ospina-Tascon G, Salgado D, Scolletta S, Vincent $J$ : Microcirculatory alterations in patients with severe sepsis: impact of time of assessment and relationship with outcome. Crit Care Med 2013, 41:791-799.

35. Iwagami M, Yasunaga H, Doi K, Horiguchi H, Fushimi K, Matsubara T, Yahagi N, Noiri E: Postoperative polymyxin B hemoperfusion and mortality in patients with abdominal septic shock: a propensity-matched analysis. Crit Care Med 2013, 42:1187-1193. 
36. The ProCESS Investigators: A randomized trial of protocol-based care for early septic shock. N Engl J Med 2014, 370:1683-1693.

37. Kaukonen KM, Bailey M, Suzuki S, Pilcher D, Bellomo R: Mortality related to severe sepsis and septic shock among critically ill patients in Australia and New Zealand, 2000-2012. JAMA 2014, 311:1308-1316.

38. Hernandez G, Bruhn A, Luengo C, Regueira T, Kattan E, Fuentealba A, Florez J, Castro R, Aquevedo A, Pairumani R, McNab P, Ince C: Effects of dobutamine on systemic, regional and microcirculatory perfusion parameters in septic shock: a randomized, placebo-controlled, double-blind, crossover study. Intensive Care Med 2013, 39:1435-1443.

39. Boerma EC, Koopmans M, Konijn A, Kaiferova K, Bakker AJ, Van Roon EN, Buter H, Bruins N, Egbers PH, Gerritsen RT, Koetsier PM, Kingma WP, Kuiper $M A$, Ince C: Effects of nitroglycerin on sublingual microcirculatory blood flow in patients with severe sepsis/septic shock after a strict resuscitation protocol: a double-blind randomized placebo controlled trial. Crit Care Med 2010, 38:93-100.

doi:10.1186/s13613-014-0030-z

Cite this article as: Hernandez et al: When to stop septic shock

resuscitation: clues from a dynamic perfusion monitoring. Annals of Intensive Care 2014 4:30.

\section{Submit your manuscript to a SpringerOpen ${ }^{\circ}$ journal and benefit from:}

- Convenient online submission

- Rigorous peer review

- Immediate publication on acceptance

- Open access: articles freely available online

- High visibility within the field

- Retaining the copyright to your article

Submit your next manuscript at $>$ springeropen.com 